\title{
Employee retention within the Information Technology Division of a South African Bank
}

\author{
Authors: \\ Joy Mohlala ${ }^{1}$ \\ Geoff A. Goldman ${ }^{1}$ \\ Xenia Goosen ${ }^{2}$ \\ Affiliations: \\ ${ }^{1}$ Department of Business \\ Management, University of \\ Johannesburg, South Africa \\ ${ }^{2}$ Department of Industrial \\ Psychology and People \\ Management, University of \\ Johannesburg, South Africa \\ Correspondence to: \\ Geoff Goldman \\ Email: \\ ggoldman@uj.ac.za \\ Postal address: \\ PO Box 524, Auckland Park \\ 2006, South Africa \\ Dates: \\ Received: 20 Oct. 2011 \\ Accepted: 30 Jan. 2012 \\ Published: 17 May 2012 \\ How to cite this article: \\ Mohlala, J., Goldman, \\ G.A., \& Goosen, X. (2012). \\ Employee retention \\ within the Information \\ Technology Division of a \\ South African Bank. SA \\ Journal of Human Resource \\ Management/SA Tydskrif vir \\ Menslikehulpbronbestuur, \\ 10(2), Art. \#438, 11 pages. \\ http://dx.doi.org/10.4102/ \\ sajhrm.v10i2.438
}

C 2012. The Authors.

Licensee: AOSIS

OpenJournals. This work

is licensed under the

Creative Commons

Attribution License.
Orientation: The information technology industry is faced with a shrinking pool of skilled employees causing demand to increase for these employees. This places organisations under pressure to devise retention strategies to retain these employees. This study was conducted in the Information Technology Division of a South African Bank.

Research purpose: To understand the challenges faced by the bank's information technology leadership team to retain employees.

Motivation for the study: To understand the challenges faced in attracting and retaining information technology professionals, and how this can serve as input for reducing skills shortages in Information Technology Divisions.

Research design, approach and method: An interpretive approach employing a case study strategy and qualitative methods was employed. Semi structured interviews were conducted with thirteen senior managers and four directors of the bank's Information Technology Division, who were selected on a purposive basis. Data were subjected to Creswell's four stage data analysis process.

Main findings: Findings indicate that employee turnover is the main contributor of skills shortages within the studied division. The lack of a retention strategy is making it difficult for leadership to identify crucial skills that must be retained.

Practical/managerial implications: Evidence suggests that this bank, although they would like to retain information technology professionals, is not creating an environment conducive to do this, as little attention is paid to the unique demands of this group of employees.

Contribution/value-add: This study investigates a specific group of employees for which a unique retention strategy does not exist. In understanding the challenges that impact on attracting and retaining information technology professionals, this study can contribute to the development of a retention strategy for these employees.

\section{Introduction}

The ability of most modern organisations to use Information Technology efficiently significantly contributes to their success. Along with this, the availability and performance of the organisation's information technology employees is crucial. Most organisations regard information technology as mission-critical and information technology employees as strategic resources (McConnell, 2004). Organisations utilise information technology professionals to plan, develop, maintain and integrate the systems used in these organisations. This dependency on information technology employees could be devastating to a business if some of the key employees were to leave. The business impact may include loss of corporate memory, disrupted projects that may over-run on defined schedules and budgets and quality issues.

It is commonly speculated that the shrinking pool of information technology professionals, currently faced by the information technology industry, is attributed to the rapidly advancing technological markets, which have resulted in a widened gap between the availability and demand of information technology professionals. In McGee's (2005) interview with companies, Gagné reports that $53 \%$ of respondents were experiencing a shortage of information technology employees. Turnover was the main reason for the shortage $(46 \%)$, followed by difficulty finding specific skills (33\%) and company growth (31\%). Gagné explains that employers were only focusing on attracting and retaining information technology employees with critical skills and experience, and not those with less critical skills. This increasing demand for skilled information technology employees has put organisations under pressure to start devising retention strategies, in order to retain the targeted employees. In order to stay abreast of this decline, technologically advanced organisations are increasingly on the lookout for highly skilled workers, whilst the labour market is dominated by individuals with limited skills (DPRU, 2006, p. 1). 


\section{An overview of relevant literature}

There are different views available in the existing literature about the definition of employee retention, the type of employees to be retained, and what approach to follow when defining a retention strategy. Browell (2003, p. 5) defines employee retention as 'keeping those members of staff that one wants to keep and not losing them from the organisation for whatever reason, especially to the competitors'. Browell (2003) further explains that key employees are those who hold positions that are critical for the success of the organisation, for example, technical positions. These are the types of positions that are seen as a source of competitive advantage.

McKeown (2002) expands on Browell's view about employee retention by mentioning that retention should be aimed only at top performing employees, and not those with a lower performance. He defines a top performing employee as the type of staff member who (McKeown, 2002, p. 8) 'adds value, contributes to the organisation overall and inspires others'. McKeown's (2002) view is that there is no precise definition of employee retention because the manager's perception of retention varies. McKeown (2002, p. 2) further explains that some managers view employee retention as 'reducing the employee turnover figure to an acceptable level' whilst others think retention is about 'compensation and benefits', moreover, some think of it as 'a component of culture', that is, how people are treated within the organisation.

Research indicates that one can identify certain factors that impact employee retention within the information technology industry. These factors are:

- Not defining desirable perks: Research (Browell, 2003; CIO Update Staff, 2006; Foote Partners, 2005; McGee, 2005) reveals that employers implemented very creative retention strategies to keep critical information technology employees on board in the escalating talent wars. For an organisation to remain competitive, it must employ the most talented people available. This means that an organisation's success is dependent on its ability to attract and retain the most talented employees (Kaye \& Vultaggio, 2004). Therefore, being able to retain the most talented employees is one of the highest critical success factors for the organisation's survival (ibid.).

- Lack of employee development: The lack of employee development has led to a major debate in the information technology industry. The topic of skills shortages has created conflicting views with information technology experts about whether or not the skills shortages is a genuine problem in the industry or results from a lack of training. Experts who oppose the view of skills shortages state that the existing skills gap problem can be attributed to employers not being willing to train their employees. Dubie (2008) explains that one of the contributing factors to information technology skills shortages is that organisations are not willing to invest time and money to train their employees. This results in advances in business and technology outpacing the ability for information technology professionals to keep up. The type of skills needed in the industry change dramatically from time to time (ibid.). This means that as the market shifts, the set of skills that were once marketable and recognised as specialised skills, are seen as common skills.

- Advancing Technology: According to the Gartner Group (cited in Gaylard, Sutherland \& Viedge, 2005), the life span of information technology knowledge is approximately 2.5 years, and is rapidly decreasing all the time. This decrease is the result of advancing technology that is now used to store, organise and easily retrieve existing information. Hira (2008) raises the concern that skills shortages must not be confused with the shortage of unique skills required to support the emerging technologies, because these skills, by definition, will always be in short supply.

- High employee turnover: Employee turnover has also been identified by information technology experts as one of the reasons that a retention strategy is needed. According to Fheili (2007), employers need to focus on the causes of employee turnover in an attempt to eradicate the effect thereof. These are typically a lack of an interesting and challenging work environment, the absence of effective two-way communication, the scarcity of opportunities to grow, and the lack of appropriate payment and compensation. Research conducted by the Chartered Institute of Personnel and Development (CIPD) (2006) revealed that the turnover of skilled employees can be problematic because recruitment is often costly as it can take several weeks to fill the available position. The CIPD stresses that it is important for the organisation to measure the costs incurred from employee turnover. Measuring these costs helps an organisation to understand the impact that employee turnover has on their budget. Once these costs are identified they are a powerful tool to encourage line managers to pay more attention to people management activities that will result in employee retention, and reduce employee turnover. The CIPD advises that providing the tangible cost of employee turnover to the executive level of an organisation is very important, especially when building a business case for an effective recruitment and comprehensive employee retention strategy.

\section{Employee retention strategy trends in the information technology industry}

The factors discussed above have helped create certain trends that have developed in the information technology industry. When an organisation decides to define its own employee retention strategy, one of the challenges it faces is to decide on the factors to consider as the foundation for that retention strategy. McKeown (2002) suggests that an organisation must start by looking at the main trends that impact employee retention in the industry. McKeown suggests the following as the prominent concepts that organisations must consider:

- Core competencies: In the current thinking on employee retention, the first concept to be discussed is that of 'core competencies'. McKeown (2002, p.12) explains his definition of core competencies as 'a bundle of skills and technologies that enables a company to provide a 
particular benefit to customers', which he bases on Hamel and Prahalad's (1990) definition. Dobson, Richards \& Starkey (2004) expand on the concept of core competencies and focus strongly on how to think about competitive advantage. Dobson et al. (2004) also use the Hamel and Prahalad definition of core competencies, that 'it's the collective learning in the organisation especially how to coordinate diverse production skills and integrate multiple streams and technologies' (Hamel \& Prahalad, 1990, p. 81). Defining the core skills will help to identify the type of employees the organisation must retain. Identifying the types of core skills that are critical to the organisation will help in defining the types of employees that require more attention and additional reward schemes. The ability to retain employees with core skills will help the organisation to perform at its peak and maintain its competitive advantage.

- The rise of free agents: McKeown (2002, p. 17) defines free agents as 'people who have become consultants or self-employed in order to gain more control over their future'. Kinnear and Sutherland (2001, p. 15) define free agents as 'the type of employees who aim not to be committed or loyal to the organisation for life, but they believe in being able to shape their own destiny'. Peters (2005, p. 33) terms this concept of shaping one's destiny as 'Brand You'. The 'Brand You' concept is the idea that an individual who works for an organisation must always behave as if he or she were the CEO of the organisation. Peters (2005) further explains that the concept of the 'Brand You' is about the attitude or some key traits that the individual possesses that identify or differentiate him or her from other employees. In an interview conducted by Peters, Pink (2005), explains how this concept came into existence. Pink states that, previously, organisations and employees used to play different roles. The organisations offered employees security and employees offered organisations loyalty. This bargain ceased to exist in the late 1980s and early 1990s when organisations started to lay off employees. Employees decided to take charge of their careers, leading to the origination of the concept of 'free agents'. Pink further explains that this does not mean that employees are no longer loyal, but the type of loyalty that now exists is no longer of a vertical nature, from individual to the organisation. Instead, loyalty now happens in multiple horizontal connections. Employees are loyal to their teams, their projects, their colleagues, and also to their families.

- War for talent: McKeown (2002) states that the concept of the 'war for talent' encompasses the acquisition, retention and performance management of the employees. He further explains that this concept gained its most exposure when McKinsey and Company issued a report titled 'The War for Talent'. This report was based on the survey undertaken by McKinsey, involving 77 companies. The report revealed that the concept of 'war for talent' suggests that there are a limited number of high calibre individuals who can perform the core competencies of an organisation. The war for talent is therefore based on the fact that different organisations are at war fighting over these individuals, trying to attract and retain them. The increasing global demand for information technology services has resulted in this 'war for talent'. The BRICS countries - Brazil, Russia, India, China and South Africa are of major and growing importance in the provisioning of information technology services (Saxena, 2007). Information technology services talent is in high demand, therefore it is important to leverage labour arbitrage. At the same time a capability play is occurring because the developed countries simply do not possess enough qualified information technology professionals to keep up with this growth (World Bank, 2007). To meet today's challenging growth targets, recruitment and retention are of key importance to all service providers (Fisher, Schoenfeldt \& Shaw, 2005; Robertson, 2007).

- Employer of choice: McKeown (2002) states that the 'employer of choice' concept is a variation of the war for talent. The 'employer of choice' concept investigates and adopts the best practices followed in retention strategies. This concept stresses that the success of employee retention can be driven through an employee management, development and reward system, all of which are necessary to develop the 'Employee Value Proposition'. Horwitz (in Delport, 2004) states that the concept of 'best employer' or 'employer of choice' is about the employer brand or organisation bias. Horwitz stresses that internal processes and culture are not sufficient for an organisation to be considered as an employer of choice if an organisation has not projected a successful external image of its 'Employee Value Proposition'. Johnson (2002, p. 23) advises that an organisation that wants to be identified as an employer of choice must have work-life balance programmes that meet the needs of its employees, it must have professional and development opportunities for all employees, it must have an employee friendly and cultural environment, and it must have business that is responsible to the community as a whole.

- Aging work force: In an interview with Kempaiah and Bullen (2008); Luftman (2008) mentions that the U.S. Bureau of Labour Statistics predicts information technology related professions to be the fastest growing profession by 2016, with more than a million jobs added between 2004 and 2014. During the interview with Kempaiah and Bullen (2008); Luftman (2008) cited research by the U.S. Bureau of Labour Statistics, which predicts an expected knowledge loss from the babyboomers (individuals born between 1946 and 1964) who will retire by 2015 . This confirms that organisations have already started to feel the impact caused by the skills shortage. These skills shortages can be attributed to the short supply of information technology skills required by organisations (ibid.). Golden (2006), reporting on a survey conducted by Accenture, highlights the importance of having a plan for transferring knowledge from the soon-to-retire information technology employees to younger information technology employees. Most of the respondents involved in this survey reported that their 
companies had no plan in place. Golden suggests that spending time planning and preparing for these soon-tobe-available vacancies can lessen the impact of losing the employees who will retire. Preparation for these vacancies can be started by grooming younger employees for these positions, which can also serve as a good retention strategy for younger employees. This can be accomplished by pairing retiring information technology employees with younger employees who are less experienced in their career, serving, as Golden suggests, the dual purpose of knowledge transfer and career development.

- Brain drain: In an interview with Dychtwald and Erickson, Melymuka (2006) advises that organisations should start preparing for the brain drain that is soon to hit the information technology industry, when the baby-boomers retire. She explains that although most of the baby-boomers will retire by 2015 , the surveys that have been conducted indicate that most of them would like to continue working even after their retirement. She advises that organisations capitalise on this opportunity and will start to develop strategies to re-integrate retired employees into organisations. Melymuka (2006) recommends that organisations can start working on their strategies by defining what she terms a 'Retiree Return Programme'. However, retiring-baby boomers are not the only challenge in terms of skills leaving the information technology sector in South Africa. Immigration of skilled workers to Europe, the USA, Australia and New Zealand has impacted on technology driven industries, and this presents a serious challenge to both retention and recruitment of information technology professionals.

From the above, the problem is found that organisations are heavily reliant upon information technology professionals. It is also apparent that South African organisations are experiencing a shortage of these highly skilled employees. Therefore, the purpose of this study is to understand the challenges facing the understudied bank's information technology leadership team when retaining employees with knowledge and skills, that are considered core to the bank's purpose of existence and continued success.

Resultant from the abovementioned problem and purpose statement, the question this study endeavours to answer is, What are the challenges faced by an organisation's leadership team in retaining information technology professionals?

\section{Research design Research approach}

This study employed an interpretive research approach applying qualitative methods. This approach was chosen on its ability to capture the lives of the participants in order to understand and to interpret the meaning thereof. Walliman (2006) explains that interpretive research is based on the view that a person can only experience the world through his or her perceptions, which are influenced by preconceived ideas and beliefs, rather than alternative forms of experiencing the world. When a researcher conducts interpretive research, he or she does not view the world externally, but from within the situation that is being studied (ibid.). This research approach, therefore, attempts to understand the phenomena being studied through the meaning and interpretations that individuals assign to them.

This study is descriptive in nature, as is aims to understand the challenges faced by an information technology leadership team, in terms of retaining information technology professionals. As such, the interpretations of this information technology leadership team, and the information technology professionals themselves, are crucial in attempting to reach the desired level of understanding.

\section{Research strategy}

This study was conducted as a single case study. Payne and Payne (2004, p. 31) define a case study as 'a very detailed research enquiry into a single example (of a social process, organisation or collective) seen as a social unit in its own right and as a holistic entity'. Payne and Payne (ibid.) further explain that the social unit is usually located in a physical place and differentiates between the people forming that social unit and other people who are not part of it. By definition, a case study will not compare two or more social areas. Payne and Payne's definition also identifies one key characteristic of a case study, that the social unit selected is a single example in its own right and of unique importance. This example is not treated as a sample, but the ideas gathered from studying this single unit can be reconsidered by other researchers and treated as contributing to knowledge.

The Information Technology Division of a South African Bank was selected as the case for study. Within these parameters, insights were solicited from various levels and functions within this division. As this study focuses on the leadership team, their perceptions and experiences, participants were selected from managerial echelons within the Information Technology Division.

\section{Research method}

Following from an interpretive research approach, qualitative research methods were employed in this study. Strauss and Corbin (1998, p. 10) define qualitative research as 'any kind of research that produces findings not arrived at by means of statistical procedures or other means of quantification'; thus the qualitative methods were decided upon as they helped to uncover the deeper understanding of this particular bank's environment.

\section{Research setting}

This study was conducted in the Information Technology Division of a leading South African Bank, which relies heavily on its information technology employees for its dayto-day operations. The challenge faced by this bank is that it has not drafted a retention strategy that is useful to ensure that these employees are retained. Individual leaders devise their own strategies within their departments. This becomes problematic as there is no uniformity in defining the type of 
resources that should be retained, the reasons for retaining them and the incentives that can be used to retain those targeted individuals. This has resulted in high employee turnover within this bank's Information Technology Division.

\section{Entrée and establishing researcher roles}

One of the researchers was employed at this particular banks' Information Technology Division and obtained permission from the employer to conduct this study on the proviso that the bank remain anonymous. As one of the researchers was employed by this bank, access to the participants had already been established. Potential participants were identified by the researcher. These candidates were approached individually to request their participation. None of the approached candidates had any objection to participate in these interviews.

\section{Sampling}

The sample for this study was selected using purposive (and therefore non-probability) sampling. What Flick (2006) terms 'case sampling' was employed here, by deciding on the type and level of participants to be interviewed. The participants interviewed emanated from the ranks of senior managers and the directors of the bank's Information Technology Division. The sample comprised of four directors and thirteen senior managers.

\section{Data collection methods}

Data were collected through the use of qualitative, semistructured interviews. Interviews provide a way of generating data by talking to people about what they do in their everyday life (Miller \& Brewer, 2003). The interviewer's main function in the interview is to provide a framework where respondents can express their views verbally (ibid.). Qualitative researchers use this type of instrument with the aim of understanding how the interviewees feel about the topic of concern. Qualitative interviews focus on gathering more in-depth information from fewer respondents (ibid.).

All interviews were conducted personally by the researcher and lasted up to one hour. The researcher limited herself to one interview per day as these were transcribed (also by the researcher) directly after each interview. Notes and memo's taken during interviews were incorporated into the transcripts. Interviews were conducted according to an interview guide where the researcher discussed a range of themes relevant to the study with the participants. All interviews were recorded onto a voice recorder for the aim of transcription and future referrals.

\section{Recording of data}

Data were recorded onto a digital voice recorder. This allowed the source data to be saved in electronic format on CD-ROM. Also, the researcher took notes of non-verbal cues during interviews and also reflected on interviews after they had been conducted. As mentioned, these notes and memos were incorporated into the transcripts to compliment the spoken word.

\section{Data analysis}

Data analysis was performed according to Creswell's (2003, p. 190) 4 stage process for conducting qualitative data analysis.

Step 1. Organise and prepare data: For this study, all the recorded data were transcribed onto Microsoft Word. The transcription was typed at the completion of each interview and not at the end of all of the interviews.

Step 2. Read through all data: A pass was made through the transcripts with the aim of gaining an overall understanding of the views of the bank's leadership team with regard to staff attraction and retention. Data were classified and grouped into themes, based on the views resulting from the data.

Step 3. Begin a detailed analysis with a coding process: In this step the emphasis shifted from memoing to describing, classifying and interpreting loop. This loop is where the coding process began. Within this step, the researcher started to move from memoing to describing, classifying and interpreting loop. This loop is where the researcher began the coding process, using the following steps:

- The researcher read each transcript of the interview document, and wrote down the topics or themes that came out of each transcript.

- The researcher then compiled a list of topics that were discovered from all the transcripts, and grouped similar topics together. A table was then created by the researcher that captured and grouped these topics. These groups were made up of common topics, unique topics and leftovers.

- The researcher then identified the descriptive words from the transcripts, which could be used for the created topics, and turned them into categories. The researcher then started to focus on reducing the list of categories by regrouping and merging the topics that related to each other.

- The last step of the coding process involved finalising the list of the categories, and then performing the preliminary analysis.

Step 4. Use a coding process to generate a description for the case study: This step displays the generated data, based on the themes appearing as major findings of the case study. This was performed by interpreting what the data uncovered. This interpretation was based on the understanding that was derived from the collected data, as well as the literature on the topic of employee attraction and retention. Coding entailed careful inspection of the data with the goal of breaking down the data into units of meaning (or categories) (Burden, 2006). This occurred through close examination of the data and ascribing labels (that constitute categories) to concepts as they present themselves in the data (Babbie \& Mouton, 2004). Data were put back together by making connections between the categories (Neuman, 2003). Thus, categories are continually being developed, but this development extends beyond dimensions and properties (Strauss \& Corbin, 1998), it also entails linkages and relationships with other categories. 


\section{Strategies employed to ensure quality data}

For qualitative research to be deemed of good quality, trustworthiness needs to be considered according to four criteria (Lincoln \& Guba, 1985):

- Credibility: This study used the whole leadership team of the Information Technology Division, and observation was persistent, as the researcher was involved in recording the interviews, taking notes and memos, transcribing the data and eventually coding the data. Furthermore, all interviews were preserved on $\mathrm{CD}$ to ensure referential adequacy of the data.

- Transferability: In this study the idea was never to illuminate further than the context of the particular bank, so transferability here pertains to how the findings are extrapolated to the entire population. In this case they can be extrapolated to the entire population as the entire population was included in the study, allowing for very thick description of data.

- Dependability: Assurance must be sought that applying the research to the same or similar research subjects in the same or similar contexts will produce similar results. Thus, if credibility is ensured, dependability is also ensured.

- Confirmability: CD back-ups of raw data and notebooks (containing field notes and memos) leave an adequate trail of how conclusions, interpretations and recommendations can be traced to their source.

Furthermore, all individuals who participated in this study did so on a voluntary basis. No coercion of participants took place. Participants were aware of the procedures followed during interviews, and gave their consent to participate with the knowledge that they could opt out of an interview at any stage if they felt uncomfortable. The participants were assured of their anonymity to those who were not directly involved in this study and all information provided in the interviews was treated confidentially.

\section{Reporting}

As this study produced a myriad of findings, this article aims to provide a bird's eye view of the retention of information technology professionals. Findings are structured according to themes emergent from the interview process. Excerpts from the interviews conducted were used to provide rich descriptions of the perceptions of the participants involved in this study.

\section{Findings}

The interviews conducted with the management team revealed that the inability to retain the type of employees with skills, that are essential to the organisation, was one of the major challenges facing this organisation. These challenges are categorised as situational factors and information technology people-specific factors. Both situational factors (consisting of industry and organisational factors) and information technology people-specific factors, influence the retention of information technology professionals. The leadership team identified the following challenges as the inhibitors to employee retention.

\section{Situational factors}

\section{Not having a retention strategy in place (organisational)}

The non-existence of an employee retention strategy was one of the issues that were raised by of the interviewees during the data collection. The interviewees indicated that the Information Technology Division has not implemented a proper strategy to which managers can refer for recruiting and retaining employees with the right type of skills. As a result, the division ended up having an uncontrollably high employee turnover rate. Interviewee (b) said:

My view is that I don't think this bank has a proper strategy in terms of employing the right people for the job and also in order to retain those people. (Interviewee b)

Interviewee (b) stated that the bank should implement a strategy that will provide guidelines for the management team about the type of people who should be attracted to and retained by the bank. Interviewee $(\mathrm{g})$ stated:

What I think the bank needs to do is a proper retention strategy. Something that is specific to various levels of performance and key skills and knowledge that we need to keep. (Interviewee g)

Interviewee (g) suggested that the strategy must provide guidance on the type of skills and knowledge that is critical to the organisation and must be retained. This suggestion also concurs with McKeown's view (2002) that organisations need to identify the types of positions and roles that are critical as a part of defining the retention strategy.

This finding can be seen as one of the main contributing factors for the unique situation in which the bank's Information Technology Division finds itself. Literature purports that a clear retention strategy is crucial to retain employees with scarce skills (Oehley \& Theron, 2010, p. 4).

\section{Not honouring promises (organisational)}

Another issue raised by the interviewees as a contributing factor to high employee turnover was that of not honouring promises. Interviewee (i) said:

... We told the staff members we are going to re-look at their salaries. The next minute we had PSA, and the next minute we stopped the salary survey. That specific incident to me did a lot of harm. (Interviewee i)

Interviewee (i) mentioned that the employees were promised that their salaries would be reviewed, but this never happened. Instead the 'PSA' exercise was conducted. This exercise basically involved the retrenchment of some of the employees. Interviewee (i) indicates that the 'PSA' exercise and the salary reviews that were not conducted did much harm.

Interviewee (h) indicated that some employees were leaving the organisation because promises were made to them upon joining the organisation and these were not kept. These promises usually relate to an employee's career growth - that is, opportunities available in the organisation that help the employee grow in his or her career. Interviewee (h) stated:

When one joined you are normally told that this is what you will do; your career growth and all that. But few months down the 
line there is another structure, new management, and new ways of doing things. What you were promised when you initially started is no longer there. (Interviewee $h$ )

Literature concurs that it is a basic tenet of sound HR practice that if an organisation does not deliver on what it has promised to staff members, those staff members will search for employment elsewhere (Hassan, 2011, p. 362).

\section{Inappropriate management style (organisational)}

The issue of the inappropriate management style used to manage the employees was also identified as a contributing factor to high employee turnover. Interestingly enough, the comments within this section were raised by the directors of this bank. Interviewee (o) said:

I think that the old saying that says people don't leave organisation, they leave managers. So our key challenge is to ensure that we have the right leadership and management in place to encourage people to stay with the organisation. (Interviewee o)

Comments made by the directors in this section and the comments that were made by the senior managers in the previous sections (that is Senior managers are not empowered to manage salary issues), indicated that there was finger pointing between the directors and the senior managers. None of the parties was willing to take the responsibility. The finger pointing also indicated that it was critical for this bank to implement a retention strategy, because that would assist in confirming the roles that must be performed by each party concerning the employee retention strategy. The requirement for clarification of roles was also confirmed by some of the comments that were made by the interviewees when asked to identify the person who is responsible for the retention of employees. The following answers were given by the interviewees: Interviewee (b) said, 'It's the line manager's function with the support of HR' (Interviewee b); Interviewee (c) said, 'Line manager' (Interviewee c); Interviewee (j) said, 'It's a collective effort, but the overall responsibility lies with the director and the line manager' (Interviewee j).

Once again, basic confusion about roles and responsibilities creates a belief amongst subordinates that support from their line managers is lacking, which in turn heightens feelings of alienation toward the organisation, as is also seen in the study of Kahumuza and Schlechter (2008, p. 17).

\section{Senior managers are not empowered to manage salary issues (organisational)}

When looking at the comments made by the interviewees, it became clear that senior managers of this bank considered themselves not to have enough authority when rewarding their employees. Interviewee (f) said:

... there are only two periods that we are allowed to do promotions. Increases are part of that but are seldom looked at. It becomes difficult to match income bracket if the person is behind ... we are trying, our hands are tied. (Interviewee f)

The comment raised by interviewee (f) indicates that management believed they were not empowered to offer employees the salaries they deserve. This can leave staff feeling disengaged. Creating engaged employees, on the other hand, can increase productivity and also reduce the likelihood of staff seeking alternative employment, as corroborated by Mostert and Rathbone (2007, p. 48-49).

\section{Ability to attract but not retain technical skills (organisational or industry)}

The bank committed much time and money travelling to road shows across the country, recruiting graduates from different institutions, and much money was spent acquiring technical resources. Interviewee (c) confirmed this by saying:

Attracting skills we are good at it but retaining current skills we are not good at that. The skill we are able to retain is more managerial rather than technical skills, especially for Group IT where the key skill is technical skill. We are unable to retain that particular skill, but we are able to attract it from outside. (Interviewee c)

This comment by interviewee (c) is cause for concern because it suggested that the bank invested more effort in retaining managerial resources compared to retaining technical resources. Some information technology experts have indicated that one of the factors contributing to high employee turnover and skill shortage, in the information technology industry, is lack of employee development. Dubie (2008) argues that organisations are not willing to invest time and money to train their employees. With the industry shifting so quickly, the advances in business and technology outpace the ability for information technology professionals to keep up with it. This change in the environment indicates that organisations need to continuously improve the skills of their employees in order to keep up with the industry. The lack of skills improvement results in the technical resources leaving organisations.

\section{Continuous restructuring (industry or organisational)}

Concern about continuous restructuring also came up several times during the interviews. Interviewee (a) also said: ' ... We need to settle the area, restructure quickly and finish and let the folks get to work' (Interviewee a).

Interviewee (f) indicated that the restructuring is often associated with employee retrenchments, and this causes instability in the working environment. Interviewee (f) said:

... If you have one [retrenchment] that's fine, but if you've had multiple the people become unsettled and they start to leave because they are not prepared to go through that amount of stress anymore. (Interviewee f)

Restructuring is synonymous with the banking sector in South Africa. However, this constant state of flux and the inability of the organisation to create anything lasting as far as structure, roles and responsibilities are concerned, creates added stress and pressure on employees, as pointed out by Goldman (2008, p. 305-306).

\section{Information technology people-specific challenges}

\section{Employees not having an interest in a job for life}

One of the interviewees pointed out that the average length of time that the graduates stay at the bank is a good example 
of employees not being interested in having a job for life within the bank. Interview $(\mathrm{m})$ indicated that the average time graduates work at the bank is approximately one to two years. Interviewee $(\mathrm{m})$ said:

... I think where the problem is, is retaining talent. We've seen that with the graduates, we do acquire them and after a year or so we tend to lose them. They are not looking for a job for life; they are looking to move quickly. (Interviewee $\mathrm{m}$ )

Interviewee $(\mathrm{m})$ raised several important points. The issue of being unable to retain graduates is a high risk for the bank when looking at the trends currently operating in the industry. Experts have predicted that the information technology industry will soon be hit by a wave of aging employees in their workforce. Therefore, organisations need to devise plans to transfer knowledge from the soonto-retire information technology employees to the younger information technology employees (Golden, 2006). As a retention strategy, organisations should start grooming younger employees to fill the positions of the soon-to-retire information technology employees. Interviewee (m) also indicated that the bank additionally needed to look at how the graduates are positioned in areas that will be of interest to them.

\section{Old type of technology is not appealing to youngsters}

Interviewee (i) also indicated that it is difficult to retain the younger generation in an environment where old technology is used. Interviewee (i) said:

It's difficult in the IT environment to retain [younger] staff. They want a challenge, they want to work on newer technology and if you do give them that opportunity to work on newer technology, you again must bring in a newer person to train and after 2 yrs they also want to leave. So it's a viscous circle. (Interviewee i)

The issues raised by interviewee (i) highlight that employees want to be challenged and also to work with newer technology. One of the reasons for their preference for newer technology is the increasing demand that goes with it. Brandel (2007) states that information technology talent shortage is only applicable to individuals with the right type of skills. In most cases the industry prefers to hire employees with the type of skills based on newer technology. Newer technology is preferred because information technology knowledge has a short life span. Gartner Group (cited in Gaylard et al., 2005) indicates that the information technology knowledge life span is between two and five years and this life span is rapidly decreasing all the time. This decrease happens because of the advancing technology that is used to store, organise and easily retrieve existing information. For this reason, the younger generation in the information technology industry are reluctant to work with old technology that is used by the legacy systems.

\section{Unattractive salaries or reward and recognition}

Richardson (2007) identifies the unattractive pay and working conditions as one of the reasons that contribute to the unhappiness of the employees. Literature indicates that these reasons eventually cause employees to become disengaged, demoralised, less committed to their work and ultimately to leaving their organisations (Kahumuza \& Schlechter, 2008; Oehley \& Theron, 2010). Interviewee (l) concurred with this by stating:

We are not rewarding the people who are sticking and stay to the bank and living the passion and the bank's values the way they are and the way they should be done. When you are not rewarding those people as a result the other banks are poaching those people. We need to take care of the people who are here. (Interviewee 1)

Interviewee (l) stated that this bank was not rewarding its employees for their hard work and their loyalty. This comment indicated that the bank did not show appreciation for their employees whom they have employed for a longer period. As a result these employees are poached by the competitors for the skills and experience that the employees have acquired over the years. There were different forms of reward and recognition that were used in the bank. Some of the interviewees indicated that these recognition initiatives have not been good enough on their own, and that employees also needed monetary reward and promotion to higher levels. Interviewee (i) said:

Pay the people, recognise the people. I think we've gone a long way with recognition, but sometimes that is also not enough they don't want the pat on the back they want money. (Interviewee i)

Interviewee (e) also agreed that there were employees who had moved to other organisations and were offered more money than they were earning in their present jobs. He also confirmed that the salary bands that are fixed within the defined grading makes it difficult to offer competitive salaries to those employees who have been offered better salaries. Interviewee (e) confirmed this by saying: '... Some people have moved for quite a bit more than what the bank is paying' (Interviewee e).

All views mentioned above were correct, but the relevance of each view was dependent on the retention definition that would be used in the division. Having a retention strategy in place would help to define the different roles that must be played by these parties. As mentioned earlier, most managers believed that their hands were tied when handling some of the employee issues such as salary negotiations or making counter offers to employees who were being head hunted.

\section{Discussion}

\section{Restating the purpose of the study}

The purpose of this study was to understand the retention challenges faced by the leadership team of this bank's Information Technology Division. Retaining information technology professionals with appropriate knowledge and skills are considered core to the bank's purpose of existence and continued success.

\section{Main contributions of the study}

Skills shortage is one of the 'hot topics' currently debated by different stakeholders in government and in the private 
sector in South Africa. The results of this study can be used as evidence to prove that skills shortages are extant, especially within the information technology industry.

Day-to-day practical solutions came forth as the management team of this bank continuously encountered skills shortages. This study became a 'platform' where the interviewed managers could think aloud and voice their opinions. The researcher believes that various initiatives will be born from the data that were generated from this study, and that the findings of this study will serve as a basis to develop a retention strategy for this bank.

\section{Relating the results to the research question}

When reviewing the research question of this study (what are the challenges faced by an organisations' leadership team in retaining information technology professionals?) two types of challenges were forthcoming. These are, firstly, situational challenges that are further disaggregated into:

- not having a retention strategy

- not honouring promises

- inappropriate management style

- managers not empowered to deal with salary issues

- ability to attract but not retain information technology professionals

- and continuous restructuring.

Secondly, the these involve information technology peoplespecific challenges that are disaggregated into:

- no interest in a job for life

- unappealing technology

- and inappropriate rewards and recognition.

\section{Relating main findings to literature}

The input provided by the management team of the understudied bank revealed that it was important for the organisation to implement a detailed employee retention strategy. This strategy must provide details on the types of employees who should be retained in the organisation. The purpose of the retention strategy was to provide direction to the management team about how to retain and look after these employees. This included defining how these employees will be managed, developed and rewarded. Interviewees wanted the strategy to provide guidelines, about how to retain key employees who want to leave the organisation for reasons relating to salaries or careers, or who are stagnating from lack of development. The interviewees suggested that the strategy must also provide guidance about the type of employees who needed to be offered counter packages when poached by competitors. Such a retention strategy must provide guidance or identify scenarios in which managers may make counter salary offers.

Experts have offered several views in existing literature on the types of employees to be retained in organisations. Browell (2003) suggests that employee retention must focus on retaining the employees who hold the type of positions that are critical to the success of the organisation. These employees are seen to be critical and the organisation cannot afford to lose them to their competitors. In contrast, McKeown (2002) suggests that retention should be aimed only at top performing employees, and not those who perform at lower levels. These are the type of employees who add value to organisations and inspire other employees. Both of these criteria suggested by Browell (2003) and McKeown (2002) were also raised by the interviewees. Views provided by this bank's management team and those cited from the literature, revealed that organisations that have no retention strategy in place, end up loosing their key resources, and as a result fail to deliver on their strategic business goals.

\section{Conclusion}

The findings of the study suggest that the retention of information technology professionals is a function of both situational challenges (which consists of interplay between industry and organisational challenges) and information technology people-specific challenges, as are seen from Figure 1. In this study, not having a retention strategy, not honouring promises, inappropriate management style, managers not empowered to deal with salary issues, the ability to attract but not retain information technology professionals, and continuous restructuring were seen as situational challenges. No interest in a job for life, unappealing technology and inappropriate rewards and recognition were viewed as information technology people-specific challenges. Figure 1 indicates that information technology people-specific challenges also indirectly affect the retention of information technology professionals (the dotted arrow). In this regard, an information technology people-specific challenge such as unappealing technology can contribute to a situational challenge such as the ability of the banking sector to attract but not retain information technology professionals.

On a more detailed level, the findings allude to the notion that the bank does not identify the unique demands of information technology staff succinctly. This is seen from the evidence provided, suggesting that the bank can attract but not retain staff. It must be borne in mind that information

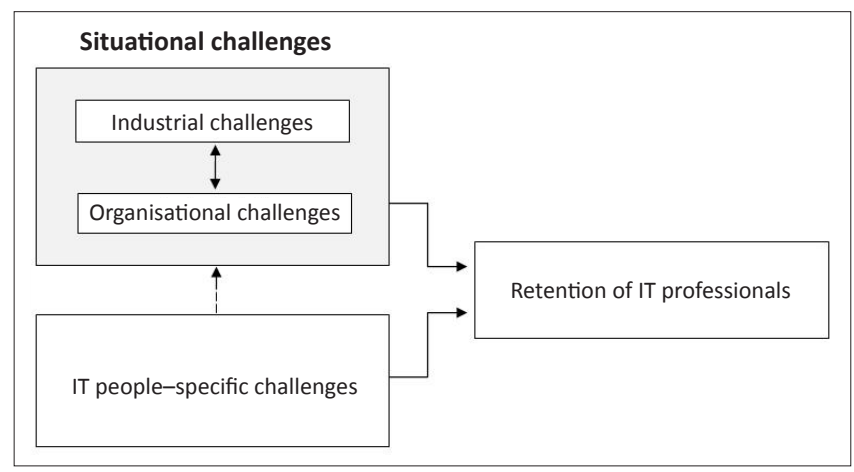

IT, information technology.

FIGURE 1: Challenges impacting the retention of information technology professionals. 
technology professionals are highly mobile, as their skills are fervently sought after. Furthermore, information technology professionals do not ascribe to a 'work-for-life ethic' and, as a rule, move between jobs rather frequently. It would seem as though information technology staff are motivated primarily by the salary and benefits they receive. Therefore, at this bank, it would seem as though they attract information technology staff, but fail to live up to the expectations for which these staff members hope (especially regarding salary and benefits), which deters them, ultimately, from retaining top information technology staff.

Although South African banks are typified by a state of constant restructuring, this lack of stability in the working environment results in promises not being honoured toward staff. This is because managers have no freedom to take decisive action, or a firm stance on issues when their whole environment is constantly in a state of flux. This, in turn, leads to the perception that managers cannot make decisions on salary issues, for example, and that there is no sense of accountability amongst managers. This overall dissatisfaction with managers further detracts from an organisation retaining information technology professionals

The evidence that suggests that information technology professionals at this bank work with old technology, which in turn leads them to disinterest in their jobs, further underscores the unique nature of the information technology professional as an individual. Being the proverbial 'computer nerd', they derive a sense of purpose in their work through engaging with the latest technology. As an information technology professional, the expectation is to have the latest technology and to upgrade this technology whenever something better, faster and more powerful is available. Outdated and obsolete technology makes it exceedingly difficult for an information technology professional to perform their vocational tasks properly, which in turn leads to frustration and feelings of dissatisfaction in the workplace, which is a deterring factor when organisations strive to retain top information technology professionals.

The evidence strongly suggests that the bank, although it would like to retain information technology professionals, is not creating an environment conducive to the retention of these professionals, as little attention seems to be paid to the unique demands of this group of employees, which, at times, is a rather demanding group of employees.

Although this study focuses on a very specific category of employee, its strength lies in its endeavor to gain a deeper understanding of the challenges involved to retain information technology professionals in a corporate setting. Over the past few decades, information technology professionals have risen in prominence in organisations. Irrespective of whether or not information technology, as a function of the organisation, is the proverbial tail wagging the dog, the fact of the matter is that information technology staff have a prominent and powerful role in organisations.
It is well known that information technology staff are nonconformists. As such, there are bound to be numerous aspects within a corporate setting that they will be at loggerheads with, as the corporation represents convention. This study, thus, reiterates the requirement for a customised outlook toward HR management in general. Put quite simply, this study supports the notion that different people should be treated differently in an organisational setting.

Secondly, this study also suggests that the retention of staff depends on a host of variables that emanate from different sources. As such, employers have a responsibility to ensure that staff turnover, of information technology professionals and other job categories, exhibits a downward trend. This is not always as easy as merely offering staff a better remuneration package. A total benefits package needs to be sought that includes benefits other than remuneration. Very often, improvement of certain organisational factors is more beneficial than a big salary increase.

In addition, the study has shown that the factors that impact on retention of information technology professionals are overwhelmingly situational factors. It is interesting to note that the majority of interview subjects were senior managers and directors, and notwithstanding, situational factors outweighed information technology people-specific factors by 6 to 3 . As banks strive to become more technology driven, it would appear from the forthcoming evidence, that the outlook is still far removed from that which typifies technology driven companies such as Microsoft or Google. Stated differently, if banks want to operate at the forefront of technology, they need to create an environment where the 'technology worker', the information technology professional, feels comfortable, driven and valued. After all, the more technology driven banks become, the more reliant they will be on information technology professionals for their prosperity.

\section{Limitations of the study}

The case study research strategy that was followed could be seen as a limitation, as it produces results, applicable to a singular context, that are not necessarily applicable to other settings. However, many HR issues are highly contextualised and warrant methods of inquiry that take cognisance of the specific context.

Further limitations included aspects such as availability of targeted participants and the time limit placed on interviews. Although the targeted research participants all agreed to be interviewed, the actual setting up and conducting of interviews was problematic as the participants' had tight schedules. With the said limited availability of participants, interviews did not exceed one hour. Thus, certain topics could not be dealt with in as much detail as expected.

\section{Avenues for future research}

It is recommended that further research be undertaken in areas other than information technology, to determine 
whether organisations experience the same challenges with the retention of professionals in these other areas or not. Further work needs to be undertaken to establish whether or not industries, other than the banking industry, find it difficult to retain their information technology staff. This study focused on the opinions of the leadership team of the understudied bank. If the debate on the challenges of the retention of information technology professionals is to be moved forward, the opinions of the information technology professionals also require consideration. Different methodologies should be considered when future research is begun on this topic as it might yield valuable additional results.

\section{Acknowledgements}

The authors would like to thank the reviewers for their diligent and constructive feedback in finalising this article.

\section{Competing interests}

The authors declare that they have no financial or personal relationship(s) which may have inappropriately influenced them in writing this paper.

\section{Authors' contributions}

J.M. (University of Johannesburg) was a Masters' student at the University of Johannesburg. As such, she conducted the fieldwork and wrote the dissertation upon which this article is based. X.G. (University of Johannesburg) and G.A.G. (University of Johannesburg) were supervisor and cosupervisor respectively. They were also equally responsible for converting the dissertation into this article, with the due consent of J.M. (University of Johannesburg).

\section{References}

Babbie, E., \& Mouton, J. (2004). The practice of social research. Cape Town: Oxford University Press.

Brandel, M. (2007). Irresistible IT Skills. Computer World, 41(32), 36-37.

Browell, S. (2003). Staff retention in a week. Great Britain: Hodder \& Stoughton.

Burden, F.J. (2006). The development of an organisational redesign model: A South African case study. Unpublished doctoral thesis. University of Johannesburg, Johannesburg, South Africa.

CIO Update Staff. (2006). Smart strategies for IT. (n.d.) Retrieved July 05, 2007, from http://www.hrmguide.net/canada/ commitment/smartretention.htm

Chartered Institute of Personnel and Development. (2006). Employee turnover and retention. (n.d.) Retrieved February 07, 2007, from http://www.cipd.co.uk/ subjecs/hrpract/turnover/empturnretent.html?IsSrchRes=1

Creswell, J.W. (2003). Research design: Qualitative, quantitative and mixed approaches. Thousand Oaks: Sage Publication.

Delport, R. (2004). Best Companies to work for. Cape Town, South Africa: Corporate Research Foundation Publishing.

Dobson, P., Richards, J., \& Starkey, K. (2004, July). The future of strategy: Competence and responsibility. Management Today, p. 1-9.

DPRU. (2006). Graduate unemployment in the face of skills shortages: A labour market paradox. Retrieved April 28, 2008, from http://www.commerce.uct. ac.za/research_units/dpru/DPRUConference2006/Papers/KPauw_Graduate Unemployment.pdf

Dubie, D. (2008). Tales of skills shortage untrue say unemployed IT professionals. Retrieved April 27, 1998, from http://www.exchangemagazine.com/morningpost /2008/week17/Wednesday/042305.html
Fheili, M. (2007). Employee Turnover: An HR risk with firm-specific context. Journal of Operational Risk, 2(3), 69-84.

Fisher, S., Schoenfeldt, L., \& Shaw, J. (2005). Human Resources Management. New York: Cengage Learning.

Flick, U. (2006). An introduction to qualitative research. London: Sage Publication.

Foote Partners. (2005). Creative IT retention strategies found in new study. (n.d.) Retrieved July 05, 2007, from http://www.footepartners.com

Gaylard, M., Sutherland, M., \& Viedge, C. (2005). The factors perceived to influence the retention of information technology. Retrieved July 06, 2007, from http:// search.sabinet.co.za/images/ejour/busman/busman_v36_n3_a8.pdf

Golden, C. (2006). Planning for Brain Drain. Retrieved June 30, 2007, from http:// www.educause.edu/ir/library/pdf/ERM06611.pdf

Goldman, G.A. (2008). Academics' experience of a merger in higher education. Unpublished doctoral thesis, University of Johannesburg, Johannesburg, South Africa.

Hamel, G., \& Prahalad, C.K. (1990). The Core Competence of the Corporation. Harvard Business Review, 68(3), 79-87.

Hassan, S.Z. (2011). Building a global IT company in a developing country through innovation - the case of NetSol from Pakistan. In Proceedings of the 20th IMDA World Business Congress, 3-7 July 2011 (pp. 359-366). Poland: Poznan.

Hira, F. (2008). Is there a tech talent shortage? Retrieved June 20, 2008, from http:// www.tmcnet.com/usubmit/2008/01/14/3209201.htm

Johnson, M. (2002). How to Become a Talent Magnet: Getting talented people to work for you. London: Prentice Hall.

Kahumuza, J., \& Schlechter, J.F. (2008). Examining the direct and some mediated relationships between perceived support and intention to quit. Management Dynamics, 17(3), 2-19.

Kaye, B., \& Vultaggio, P. (2004). The development minded manager. Retrieved April 08, 2008, from http://www.hr.com/.../the-development-minded-manager ead179wf.html

Kempaiah, R., \& Bullen, C. (2008). Skills famine? Retrieved April 06, 2008, from http:// www.informationweek.com/news/management/compensation/showArticle.jht $\mathrm{ml}$; jsessionid=05HJIOZ3LIOVCQSNDLPSKHOCJUNN2JVN?articleID=206903580\& requestid $=224355$

Kinnear, L., \& Sutherland, M. (2001). Money is fine, but what is the bottom - line? Journal S.A. Institute People Manage, 19(1), 15-18.

Lincoln, Y.S., \& Guba, E.G. (1985). Naturalistic Inquiry. Newbury Park: Sage.

Luftman, J.N. (2008). Key Issues for IT Executives. MIS Quarterly Executive, 7(2), 12-20.

McConnell, T. (2004). Retention for IT Professionals. Retrieved July 02, 2007, from http://www.mcconnellhrc.com/assets/article/retention strategies for it professionals.pdf

McGee, M.K. (2005). Retention tension. Retrieved July 02, 2007, from http://www. informationweek.com/news/showArticle.jhtml?articlelD $=173403018$

McKeown, L.J. (2002). Retaining top employees. Retrieved June 30, 2007, from http:// www.briefcasebooks.com/mckeown01.pdf

Melymuka, K. (2006). Work force crisis - ready or not IT talent crunch is coming. How to prepare. Retrieved November 08, 2007, from http://www.emeraldinsight.com/ Insight/viewPDF.jsp?Filename=html/Output/Published/EmeraldFullTextArticle/ Pdf/0060321102.pdf

Miller, R.L., \& Brewer, J.D. (2003). The A-Z of social research. London: Sage Publications.

Mostert, K., \& Rathbone, A.D. (2007). Work characteristics, work-home interaction and engagement of employees in the mining industry. Management Dynamics, 16(3), 36-52.

Neuman, W.L. (2003). Social Research Methods: Qualitative and quantitative approaches. Boston: Allyn \& Bacon.

Oehley, A.M., \& Theron, C.C. (2010). The development and evaluation of a partial talent management structural model. Management Dynamics, 19(3), 2-28.

Payne, G., \& Payne J. (2004). Key concepts in social research. London: Sage Publication.

Peters, T. (2005). Essentials - Talent: Develop it, sell it, be it. United Kingdom: Dorling Kindersley Limited.

Pink, D.H. (2005). A whole new mind: Why right-brainers will rule the future. USA: Riverhead Books.

Richardson, S. (2007). What is a skill shortage? Retrieved April 27, 2008, from http://eric.ed.gov/ERICDocs/data/ericdocs2sql/content_storage_01/0000019b/ 80/28/06/09.pdf

Robertson, I. (2007). Factors influencing vocational teacher's use of online functionalities in Australia. Australasian Journal of Educational Technology, 23(3), functiona $371-389$.

Saxena, A. (2007). BRIC: India Executive Market Watch. Q1 June 2007. Framingham, MA: International Data Corporation.

Strauss, A., \& Corbin, J. (1998). Basics of qualitative research: Techniques and procedures for developing grounded theory. London: Sage Publications.

Walliman, N. (2006). Social research method. London: Sage Publications.

World Bank. (2007). Global economic prospects, managing the next wave of globalization. Washington DC: The World Bank. 